\title{
ISI PESAN DAKWAH AQIDAH DAN SYARIAH DALAM FILM INDONESIA ISLAMI “JILBAB TRAVELER LOVE SPARKS IN KOREA” (Kajian Semiotik pada Film Islami Indonesia)
}

\author{
Masturina Khoirun Nisa, Ucik Ana Fardila, Agus widodo \\ Prodi Komunikasi dan Penyiaran Islam, IAIN Tulungagung \\ E-mail : masturina.khoirun.nisa@gmail.com, fardillaucikana@gmail.com, \\ Aguswidodo88@gmail.com
}

\begin{abstract}
This research purposed to determine the preaching messages of aqeeda and sharia in the movie "Jilbab Traveler Love Spark in Korea". The methode of the research used qualitative approachment of Ferdinand de Saussure semiotic analysis to determine the meanings of every adegans, texts, sounds, dialogues, sounds, videos and symbols in the movie. The results of this research showed that there are preaching messages of tafakkur, istighfar, and dzikr in the movie. The preaching messages in sharia aspects are praying, dresses, fasting, sadaka, sincerity (ikhlas) attitude, obidient to alcohols and porks prohibition. The preaching messages in muamalat aspects are obidient to Islam's law, discussing polygamy issues and to follow premarital process of Islam before marriage (khitba and taaruf).
\end{abstract}

Keywords: preaching message, movie analysis, Semiotic Analysis

\section{Pendahuluan}

Film terus mengalami perkembangan yang sangat pesat bersamaan dengan perkembangan dan kemajuan teknologi pendukungnya. Film yang awalnya hanya berupa gambar hitam putih, bisu dan bergerak sangat cepat kemudian berkembang hingga seperti yang bisa kita tonton saat ini yaitu bisa bersuara, berwarna dengan berbagai macam efek yang lebih dramatis. Sepak terjang perkembangan seni perfilman pun juga dialami oleh Indonesia yang pertama kali memperkenalkan film dokumenter tentang perjalanan Ratu dan Raja di Den Haag pada 5 Desember 1900 di Batavia (Jakarta) yang lalu hingga mampu menayangkan ratusan film hari ini. Kerja keras yang dilakukan oleh siematografi Indonesia untuk menampilkan film yang lebih berkualitas di layar lebar kini sudah bisa dinikmati oleh khalayak.

Dunia perfilman saat ini film mampu merebut perhatian masyarakat Indonesia. Film telah menjadi kajian Komunikasi Massa karena aktivitas menonton menciptakan komunitas sendiri, yang di dalamnya terdapat penerapan ilmu komunikasi massa. Pesan berupa isi film, dikirimkan melalui media bioskop 
atau media menonton lain, sampai ke tangan penerima pesan, yaitu penonton. Isi pesan film dapat terlihat dari judul, konten film, tema film, adegan, aktor, dan sebagainya unsur teks, audio, video, dan simbol yang tercantum di dalam film.

Sutradara Guntur Soeharjo didalam naungan Rapi Films memproduksi film islami dengan judul "Jilbab Traveler Love Sparks In Korea", yang merupakan film drama percintaan sekaligus drama dokumentasi perjalanan perempuan berjilbab di beberapa kota di dunia. Film ini sibuat berdasarkan novel dengan judul sama penulis Asma Nadia terbitan tahun 2009 oleh penerbit Asma Nadia Publishing House.

Sinopsis film adalah sebagai berikut:

"Rania Samudra (diperankan Bunga Citra Lestari) adalah seorang penulis berusia 24 tahun dengan kegemaran traveling dan mendapatkan sebutan "Jilbab Traveler" oleh para pembacanya. Pada saat Ayah Raina sakit, Rania memutuskan pulang tetapi Ayahnya meminta Rania mengunjungi Baluran, Jawa Timur, tempat Ayah dan Ibu Rania bertemu untuk pertama kali. Di Baluran Rania bertemu dengan Hyun Geun (diperankan oleh Morgan Oey), fotografer asal Korea dan sahabatnya, Alvin (diperankan Ringgo Agus), yang meminta Rania memandu ke lokasi "Kawah Ijen." Raina yang beralih menjadi pemandu wisata dan melupakan keinginan ayahnya membuat Raina menyesal hingga mengambil keputusan berhenti menjelajah dunia. Di saat itu Hyun Geun berusaha melakukan pendekatan kepada Raina, tetapi karena Raina tidak memberikan tanggapan Hyun Geun kembali ke Korea. Rania yang merasa bersalah berusaha mendampingi orang tuanya di rumah hingga dua kakak Rania berkeinginan menjodohkan Rania dengan Ilhan (diperankan oleh Giring Ganesha). Pada awalnya Raina merasa siap menerima Ilhan sebagai pasangan tetapi setelah menerima undangan peserta Writers in Residence di Gangwon, Korea Selatan, Rania mulai merasa bimbang dan di saat yang sama Raina mengingat kembali kenangan dengan Hyun Geun."

Film tersebut disutradarai oleh Guntur Soeharjanto, penulis naskah Alim Sudio, pemain utama: Bunga Citra Lestari, Morgan Oey, Giring Ganesha, durasi 112 menit, tanggal penayangan perdana pada 5 Juli 2016 (IDFC, 2016).

Film menjadi salah satu pengetahuan yang dipelajari di ilmu Komunikasi Massa sebagai aspek fenomena perubahan budaya manusia secara massal. Penelitian tentang film telah dilakukan ketika para ahli komunikasi menganggap film memenuhi kebutuhan banyak orang, baik dengan memberikan hiburan, pengetahuan, hingga memengaruhi opini publik. Di Amerika perkembangan film 
dapat menjadi tolok ukur perkembangan budaya demokrasi politik. Pada tahun 1940 - 1950an film-film di Amerika disebut beraliran 'mainstream' yang menunjukkan budaya konservatif saat itu. Pada tahun 1960an film berkembang ke pemenuhan selera pemuda di saat budaya politik dipenuhi gerakan-gerakan pemuda. Film terbukti memengaruhi opini publik terutama melalui film dokumenter, misalkan film Fahrenheit 9/11, World Trade Center, United 93, yang mengkaji peristiwa serangan teroris pada 11 September 2001 (Lule, 2010: 343). Saat ini tidak hanya film produksi Hollywood sumber satu-satunya film masyarakat, melainkan melalui berbagai platform. Perkembangan industri film di dunia, termasuk industri perfilman nasional di Indonesia, kemudian perkembangan teknologi memberikan banyak pilihan film kepada publik, yaitu di bioskop, di rumah, atau melalui telepon pintar. Ketiga media tersebut memiliki karakter budaya tersendiri sehingga semakin mengembangkan area penelitian dari berbagai aspek ilmu pengetahuan.

\section{Metode Penelitian}

Metode penelitian ini menggunakan jenis penelitian kualitatif dengan metode analisis semiotika Ferdinand de Saussure. Di dalam catatannya tentang bahasa pada buku "Cours de Linguistique Générale" Saussure menyebutkan bahwa simbol terdiri dari dua bagian yaitu: "significant" signifier dan "signifié" signified. Pertama, bagian fisik yang disebut penanda (signifier), yaitu bahasa terlihat. Kedua, bagian konseptual yang disebut petanda (signified), yaitu bahasa konsep atau yang tidak terlihat (Saussure, 1916: 15). Saussure mengatakan "petanda dan penanda merupakan suatu kesatuan, bagaikan dua sisi dari sehelai kertas" (Alex Sobur, 2004:46). Dengan kata lain, penanda merupakan bunyi yang bermakna atau coretan-coretan yang bermakna. Menurut Sausure, bahasa merupakan suatu sistem tanda (sign). Suara-suara, baik itu suara manusia, hewan, atau bunyi-bunyian, hanya dapat dikatakan sebagai bahasa apabila suara atau bunyi tersebut mengekspresikan, menyatakan, atau menyampaikan ide-ide dan pengertian-pengertian tertentu. Jadi penanda adalah aspek material dari bahasa, yakni apa yang dikatakan atau di dengar, apa yang ditulis, dan apa yang dibaca. Sedangkan petanda merupakan gambaran mental, pikiran, atau konsep dari bahasa 
tersebut. Suara dari yang muncul dari sebuah kata yang diucapkan merupakan penanda (signifier), sementara konsepnya adalah petanda (signified). Contohnya: Seseorang mengatakan kata jangkrik, maka kata jangkrik ini adalah penandanya (signifier), sedangkan petandanya (signified) bisa jadi sebuah nama hewan ketika diucapkan dengan nada datar, atau sebuah kata kotor yang diungkapkan saat orang tersebut sedang kesal, marah, atau sial ketika diucapkan dengan nada meninggi.

Sumber data digunakan sumber primer dan sekunder. Pertama, data primer yang merupakan adegan-adegan di film "Jilbab Traveler Love Sparks In Korea" dalam bentuk audio visual. Selain itu, data-data yang juga dinilai memiliki hubungan dengan objek penelitian. Kedua, data sekunder yang diperoleh dari sejumlah literatur pustaka seperti buku, situs internet, dan lainnya yang berkaitan dengan objek penelitian. Penelitian dilakukan dengan menganalisa adegan, meliputi teks, audio dan video pada film “Jilbab Traveler Love Sparks in Korea”.

\section{Pembahasan}

Hasil penelitian mengenai pesan dakwah yang terkandung dalam film "Jilbab Traveler Sparks in Korea" peneliti memfokuskan pada pesan dakwah dari segi Aqidah dan Syariah.

Setelah data dikumpulkan, maka dapat ditemukan pesan dakwah Aqidah dan Syariah dalam film “Jilbab Traveler Sparks in Korea” yaitu :

\section{A. Pesan dakwah Kategori Aqidah}

Aqidah merupakan keyakinan hati dan pembenaran terhadap sesuatu yang meliputi Iman kepada Allah, Iman kepada Malaikat-malaikat-Nya, Iman kepada Kitab-kitab-Nya, Iman kepada Rasul-rasul-Nya, Iman kepada Hari Kiamat dan Iman Kepada Qada dan Qodar yang baik maupun buruk (Bashori,2013:3), pesan dakwah yang terkandung dalam film “Jilbab Traveler Love Spark in Korea antara lain :

\section{Pesan Dakwah Tafakur}

Pesan dakwah mengenai tafakur terdapat dari narasi tokoh Rania pada awal cerita yaitu adegan detik ke 00:02:36. Rania menjelaskan tujuannya ketika menjelajahi dunia salah satunya yaitu menapaki bumi untuk mentafakuri ayat ayat Allah. Tafakur yaitu berpikir dan merenungkan dengan sungguh-sungguh 
akan kebesaran Allah SWT yang salah satu medianya bisa menggunakan ayatayat Allah yakni Al-Qur'an. Allah sangat menekankan tafakur dan menempatkan kaum yang suka berpikir pada derajat yang tinggi, karena dengan berpikir manusia dapat menjalankan tugas-tugasnya, lebih meningkatkan ketakwaannya kepada Allah SWT, dan meningkatkan pemahaman manusia tentang ajaranajaran-Nya. Contoh tentang tafakur terdapat dalam Q.S. Ar-Rum [30] ayat 8

\section{Pesan Dakwah Mengucap Kalimat Syukur}

Pesan dakwah syukur terdapat dalam dialog tokoh ayah Rania dalam adegan detik ke 00:04:37. Pada bagian ini Rania baru saja pulang dari perjalanannya ke luar negeri, begitu sampai di kamar ayahnya, ayah Rania menyambut kedatangannya dengan bangga. Ayah sangat bersyukur karena Rania telah mewakilinya untuk melihat dunia.

Bersyukur merupakan berterima kasih atas segala limpahan rahmat yang telah Allah SWT berikan kepada kita. Allah SWT sangat menekankan perihal syukur kepada manusia. Dalil tentang syukur salah satunya di jelaskan dijelaskan dalam firman Allah Q.S. Ibrahim [14] ayat 7.

\section{Pesan Dakwah Mengucap Kalimat Istirja Ketika Mendengar Kabar Duka.}

Pesan dakwah tentang mengucap istirja terdapat dalam dialog tokoh Alvin sedang memberi tahu Rania bahwa Ibu Hyun Geun meninggal dunia pada adegan detik ke 00:35:06. Kalimat istirja diucapkan oleh umat muslim ketika tertimpa musibah dan apabila mendapatkan kabar duka, sebagai bentuk berserah diri kepada Allah dan bersyukur atas segala yang mereka terima. Anjuran mengucap kalimat Istirja' yang berbunyi Innalillahi wa inna ilaihi raaji'un saat ditimpa musibah baik kecil maupun besar terdapat dalam firman Allah swt dalam Q.S. AlBaqarah Ayat 156-156. Ayat tersebut mengandung balasan yang didapatkan oleh manusia yang mau ber-istirja yaitu akan mendapatkan ampunan dari Allah SWT di dunia agar terhindar dari azab di akhirat, dan mereka itulah orang-orang yang mendapat petunjuk. 


\section{Pesan Dakwah Mengucap Istighfar}

Film "Jilbab Traveler love Sparks In Korea" menampilkan beberapa adegan yang mengandung pesan dakwah mengucap istighfar, salah satunya pada adegan dialog tokoh Ibu Rania ketika akan menikmati makan malam bersama keluarga. Tiba-tiba Ibu Rania menyuruh Rania untuk memanggil ayahnya agar bisa makan bersama, setelah itu Ibu Rania sadar bahwa suaminya sudah meninggal, Ibu pun segera mengucap istighfar sebanyak tiga kali. Adegan ini terdapat pada detik ke 00:19:44. Istighfar merupakan permohonan ampunan kepada Allah atas segala dosa dan kesalahan (Ghunaim,2013:1). Kalimat “Astaghfirullahal-adzim" diucapkan oleh umat islam untuk mohon ampun kepada Allah, atau untuk mencegah dari melakukan perbuatan yang salah, dan lebih jauh lagi istigfar diucapkan untuk selalu mengingat Allah disaat ia tergoda untuk melakukan kesalahan atau dosa (bertaubat). Anjuran tenteng bertaubat di dalam Al-Qur'an disebutkan beberapa kali, salah satunya dalam Q.S. An-Nisa Ayat 110 yang berbunyi.

\section{Pesan Dakwah Mendekatkan Diri Kepada Allah}

Pesan dakwah mendekatkan diri kepada Allah terdapat pada adegan detik ke 00:48:01 yaitu dalam dialog tokoh Alvin yang sedang menceritakan keadaan Hyun Geun selama di Korea.

Seorang muslim harus selalu mendekatkan diri kepada Allah SWT, bahkan mencari kedudukan yang terdekat dengan-Nya, firman Allah tentang mendekatkan diri kepada-Nya juga terdapat dalam dalam Q.S. Al-Ma'idah ayat 35.

\section{B. Pesan dakwah kategori Syariah}

Pesan dakwah kategori Syariah dibagi menjadi dua aspek. Pertama, aspek ibadah yang berarti aturan tentang hubungan manusia dengan Allah SWT yang terdiri dari rukun islam. Kedua, aspek muamalah yang berarti aturan-aturan tentang hubungan manusia dengan manusia dalam rangka memenuhi kepentingan dan kebutuhan hidup, baik itu primer maupun sekunder. 


\section{a. Pesan Dakwah Kategori Syariah Ibadah Terdiri Dari : 1) Pesan Dakwah Sholat}

Film “Jilbab Traveler Love Sparks in Korea” mengandung pesan dakwah sholat yang ditunjukkan ke dalam empat kali adegan. Salah satu Pesan dakwah sholat terdapat dalam adegan detik ke 01:02:20 yang bisa dilihat dari dialog tokoh Rania dan seorang laki-laki penduduk Korea.

Dalam adegan ini menampilkan pesan dakwah tentang sholat. Sholat harus selalu ditegakkan dalam kesempatan apapun dan ketika di negeri orang yang mayoritas penduduknya non muslim sekalipun. Banyak sekali ayat-ayat AlQur'an yang membahas tentang perintah sholat, salah satunya adalah firman Allah dalam Q.S. Al-Baqarah Ayat 45.

\section{2) Pesan Dakwah Tentang Berdo'a, Sholat Safar Dan Sedekah Dapat Menolak Bala}

Pesan dakwah mengenai hal ini terdapat dalam dialog Tokoh Rania dan Ilhan. Ilhan yang takut menjadi penumpang pesawat terbang bertanya kepada Rania dalam adegan detik ke 00:32:12. Dalam adegan tersebut mengandung tiga pesan dakwah yaitu : berdo'a, anjuran sholat safar yaitu sholat sunah yang dilaksanakan sebelum berpergian jauh dan bersedekah untuk menolak balak. Ketiga hal tersebut bisa menghindarkan kita dari mara bahaya ketika berpergian. Dalil Al-Qur'an tentang Do'a terdapat dalam Q.S Al-Baqarah ayat 186. Selanjutnya umat Islam dianjurkan untuk melakukan sholat Safar sebelum melakukan perjalanan, hal ini dijelaskan oleh Nabi Muhammad dalam hadits riwayat Al-Bazzarr.

Selain berdo'a dan sholat safar ketika akan berangkat dalam perjalanan, umat islam juga dianjurkan untuk bersedekah. Banyak sekali manfaat dari bersedekah, salah satunya dapat menolak bala atau musibah. Akan tiba saatnya setiap orang terkena bala atau musibah yang sudah ditentukan dalam hidupnya. Menurut Rasulullah SAW terdapat satu amalan yang dapat menolak bala atau musibah yaitu sedekah. Bala tersebut akan diangkat oleh Allah SWT sebab amalan yang telah ia perbuat. 


\section{3) Pesan Dakwah Alkohol Haram}

Pesan dakwah tentang Alkohol haram terdapat dalam adegan detik ke 00:11:35. Hal ini dapat dilihat dalam adegan ketika tokoh Hyun Geun yang sedang meminum alcohol, lalu ia menghampiri tokoh Rania yang sedang duduk, ia menawarkan minuman tersebut kepada Rania. Rania menolak minuman tersebut tetapi Hyun Geun pun tetap memaksanya sampai pada akhirnya tokoh Alvin datang memberitahu Hyun Geun bahwa hukum meminum alkohol adalah haram.

Alkohol adalah minuman memabukkan yang memiliki sifat dan zat-zat yang sama dengan khamr. Di dalam Al-Qur'an terdapat beberapa ayat yang menjelaskan hukum meminum khamr adalah haram.Salah satu penyebab haramnya khamer karena manfaatnya yang lebih sedikit dari kemudhorotannya, sebagaimana firman Allah dalam Q.S. Al-Baqarah ayat 219.

\section{4) Pesan Dakwah Haram Memakan Babi Dan Kewajiban Memakan Makanan Yang Halal}

Pesan dakwah tentang haram memakan babi dan diharuskan memakan makanan yang halal terdapat dalam dialog tokoh Ajumoni dan tokoh Rania. Dalam adegan ini Rania baru saja sampai di Korea dan disambut oleh Ajumoni. Ajumoni mengajak Rania untuk ke ruang makan, adegan detik ke 00:45:11.

Allah SWT melarang umatnya untuk memakan beberapa makanan dan sangat menekankan memakan makanan yang halal. Makanan yang haram dimakan diantaranya adalah babi dan beberapa hewan lainnya yang terdapat firman Allah dalam potongan Q.S Al-Maidah ayat 3. Selain mengandung pesan dakwah haram memakan babi, film “Jilbab Traveler Love Spark in Korea” juga mengajarkan kita untuk selalu memakan makanan yang halal. Tidak ada alasan bagi kita untuk memakan makanan selain yang dihalalkan, baik dari segi kandungan yang terdapat dari makanan itu sendiri maupun dari segi memperolehnya. Kewajiban umat islam untuk memakan makanan yang halal dijelaskan dalam Q.S. Al-Maidah ayat 88. 


\section{5) Pesan Dakwah Menutup Aurat}

Pesan dakwah menutup aurat yang disampaikan dalam film "Jilbab Traveler Love Sparks in Kore" adalah tentang berjilbab maupun mengenakan pakaian muslim yang tertutup dan sesuai syariah. Pesan dakwah ini salah satunya terdapat dalam narasi tokoh rania pada adegan detik ke 01:04:16.

Aurat merupakan bagian anggota tubuh yang harus ditutup dan tidak boleh diperlihatkan kepada orang lain. Aurat yang tercantum di dalam Al-Qur'an diterapkan setidaknya pada saat umat Islam menjalankan kewajiban sholat. Bagi perempuan auratnya adalah seluruh tubuh dengan bahan kain tidak memerlihatkan lekuk dan harus menutup semua bagian tubuh kecuali bagian wajah dan telapak tangan. Sedangkan bagi laki-laki aurat didefinisikan sebagai bagian tubuh yang harus ditutupi meliputi perut hingga lutut. "Jilbab Traveler Love Spark in Korea” adalah kewajiban muslimah untuk memakai pakaian yang tertutup dan mengenakan jilbab. Bagi perempuan menutup seluruh anggota badan merupakan keniscayaan karena merupakan perintah agama Islam. Kewajiban muslimah untuk menutup aurat dijelaskan di dalam Al-Qur'an Q.S. An-Nur ayat 31.

\section{b. Pesan dakwah kategori syariah muamalah terdiri dari :}

\section{1) Pesan dakwah bekerja dengan cara yang halal}

Film “Jilbab Traveler Love Sparks in Korea” juga mengajarkan kita untuk bekerja dengan cara yang halal. Hal ini disebutkan oleh tokoh Rania ketika menceritakan pekerjaannya, adegan detik ke 00:03:28 .

Setiap muslim dianjurkan untuk menjaga nafkah dirinya dan keluarganya sedapat mungkin dengan cara yang halal dan baik. Kewajiban mengetahui halal haram dalam mencari pekerjaan dikarenakan Allah S.W.T. memerintahkan untuk makan dari yang halal dan mengharamkan cara-cara yang batil dalam memperoleh harta. Allah S.W.T. berfirman dalam Q.S Al-Baqoroh ayat 172. Dalam ayat ini Allah SWT memerintahkan kepada kita untuk memakan makanan yang baik-baik dari yang telah Allah S.W.T. berikan kepada mereka, dan hendaknya mereka bersyukur kepadanya jika mereka hamba-Nya. Makan dari yang halal bisa menjadikan diterimanya do'a dan ibadah, sebagaimana makan dari yang haram menghalangi dikabulkannya do'a dan ibadah. 


\section{2) Pesan Dakwah Poligami}

Poligami merupakan persoalan klasik yang tetap menarik untuk di bahas dan sudah tidak asing lagi di negara Indonesia. Pesan dakwah dalam film "Jilbab Traveler Love Sparks in Korea” tentang poligami terdapat dalam adegan detik ke 00:03:56 yakni dalam dialog tokoh Rania dengan wanita berkewarganegaraan asing.

Seorang laki-laki diperbolehkan beristri lebih dari seorang, tetapi dibatasi hanya empat orang saja, hal ini dijelaskan dalam Q.S. An-Nisa ayat 3. Di dalam film ini aktor Raina berupaya menjelaskan gagasan berpoligami dalam Islam, yaitu bahwa walaupun seorang laki-laki yang beristri lebih dari satu berusaha untuk berbuat adil tetap saja ia tidak bisa berlaku adil, karena makna adil bukanlah dilihat dari besarnya nafkah berupa materi yang diberikan kepada istri, akan tetapi juga mengenai besarnya cinta dan kasih sayang, sehingga berbuat adil itu bisa dikatakan sangat sulit.

\section{3) Pesan Dakwah Khitbah}

Pesan dakwah tentang khitbah atau meminang terdapat dalam dialog Ihan dan Rania adegan 01:25:58. Khitbah atau meminang bisa diartikan sebagai meminta wanita untuk dijadikan istri (bagi diri sendiri atau orang lain) baik itu gadis maupun janda. Khitbah atau meminang terdapat tata cara dan syarat tersendiri dalam ajaran islam, sehingga para laki-laki juga harus memperhatikan hal-hal tersebut. Salah satu firman Allah tentang khitbah terdapat dalam surat AlBaqarah ayat 235. Ayat tersebut menjelaskan cara meminang perempuan yang sedang menjalani masa iddah akibat cerai hidup atau cerai mati. Jadi di dalam islam adab, tata cara dan syarat meminang seorang perempuan telah di atur dalam Al-Qur'an maupun hadis nabi, sehingga kita juga harus mematuhi kaidah-kaidah tersebut.

\section{Kesimpulan}

Berdasarkan pembahasan pada bab sebelumnya, maka penulis memperoleh kesimpulan sebagai berikut : Pesan dakwah yang terkandung dalam Film "Jilbab Traveler Love Sparks In Korea" meliputi sub kategori Pesan dakwah kategori aqidah terdiri dari pesan dakwah tafakur, bersyukur, mengucap 
istirja', beristighfar, dan mendekatkan diri kepada Allah. Pesan dakwah kategori syariah dalam aspek ibadah terdapat pesan dakwah menunaikan sholat, berdo'a, sholat safar, dan sedekah untuk menolak bala, alkohol haram, haram memakan babi dan kewajiban memakan makanan yang halal, dan menutup aurat, sedangkan pesan dakwah dalam aspek muamalah terdapat pesan dakwah bekerja dengan cara yang halal, poligami, dan khitbah.

\section{Saran}

Dari kesimpulan diatas maka penulis menyampaikan beberapa saran agar dapat dijadikan pertimbangan serta evaluasi terhadap film "Jilbab Traveler Love Sparks In Korea" sekaligus memberikan inspirasi baru bagi industri film Indonesia.

1. Kepada penggemar film dan para pembaca diharapkan bisa lebih selektif dalam menonton film yaitu tidak hanya melihat dari sisi hiburan semata tetapi juga memperhatikan pesan atau pelajaran yang di dapatkan setelah menonton film tersebut.

2. Bagi industri perfilman Indonesia diharapkan untuk lebih banyak membuat karya film bertajuk religi yang menyisipkan pesan-pesan dakwah, sehingga dapat mendidik dan menyebarkan kebaikan kepada pemirsanya.

\section{Daftar Pustaka}

Bashori, Agus Hasan. 2013. Kitab Tauhid 1. Jakarta : Darul Haq.

El-Bantanie, Muhammad Syafi'ie. 2010. 7 Amalan Penarik Rezeqi. Jakarta: PT Elex Media Komputindo.

Ghunaim, Hani Sa’ad. 2013. Cinta Istighfar. Jakarta : Amzah.

Hafizhah, Abu. 2010, Makanan yang Diharamkan. Ponorogo: Islamic Center Abdullah Ghanim As-Sama'il.

Ilaihi,Wahyu. 2010. Komunikasi Dakwah. Bandung: PT Remaja Rosdakarya.

Mahmud, Ali Abdul Halim. 2010. Rukun Taat. Solo: PT. Era Adicitra Intermedia

Shihab, M. Quraisy . 2004. Tafsir Al-Misbah: Pesan, Kesan dan Keserasian Alquran Vol 1 Jakarta: Lentera Hati.

Sobur Alex. 2004. Semiotika Komunikasi. Bandung: PT Remaja Rosdakarya. 
Syukur, Yanuardi . 2010. Jadikan Musibah sebagai Ladang Ibadah. Jakarta: AlMaghfirah.

Lule, Jack. 2010. Understanding Media and Culture: An Introduction to Mass Communication. University of Minnesota Libraries Publishing. Minnesota, US.

Indonesian Film Critics. 30 Juni 2016. Review: Jilbab Traveler: Love Sparks in Korea (2016). IDFC. Sumber: http://idfilmcritics.com/indonesianmovie/jilbab-traveler-love-sparks-in-korea-2016-review/. Diunduh pada 30 Maret 2019.

Saussure, F. de., (Ed.) Bally \& Sechehaye. 1922. Cours De Linguistique Générale (1916). 2d ed. Payot, Lausanne and Paris. France. 